\title{
Research on Time-Variant Wear Reliability of Gear Rack
}

\author{
Chen $\mathrm{Li}^{1,}$, , Wang Decheng ${ }^{1}$, Liu Hongqi ${ }^{1,2}$, Cheng Peng ${ }^{1,2}$, Shao Chenxi ${ }^{1,2}$ \\ ${ }^{1}$ China Academy of Machinery Science \& Technology, Beijing, China \\ ${ }^{2}$ China Productivity Center for Machinery, Beijing, China
}

Email address:

88603943@qq.com (Chen Li),wangdc@cam.com.cn (Wang Decheng)

${ }^{*}$ Corresponding author

\section{To cite this article:}

Chen Li, Wang Decheng, Liu Hongqi, Cheng Peng, Shao Chenxi. Research on Time-Variant Wear Reliability of Gear Rack. International Journal of Mechanical Engineering and Applications. Vol. 5, No. 2, 2017, pp. 112-117. doi: 10.11648/j.ijmea.20170502.16

Received: April 4, 2017; Accepted: April 18, 2017; Published: April 21, 2017

\begin{abstract}
In this paper, a gear rack of a ship lift is taken as an example. This paper presents a method for analyzing the reliability of gear and rack movement under the influence of time-varying wear. The example of large modulus gear rack mechanism for ship lift is verified. Through the wear state of rack and pinion, the time dependent reliability equation of kinematic pair is established with the consideration of the original dimension error, gap error and wear effect. Based on the Archard wear model, the hardness and other factors under the influence of time variation are analyzed and the new kinematic pair model is established. Finally, the Matlab software is used to simulate the wear process of the rack and pinion. The influence degree of the above factors on the motion reliability of mechanism is analyzed. The results of simulation and analysis show that the method is more accurate and suitable for engineering application. It provides an important reference for the life prediction of gear rack and the development of maintenance and maintenance outline.
\end{abstract}

Keywords: Gear Rack, Time-Variant Reliability, Motion Reliability

\section{Introduction}

In recent years, with the increasing development and application of heavy load of large mechanical equipment, the mechanical reliability assessment stage from design have been great attention and in-depth study, however, compared with the mechanism of strength reliability, according to the characteristics of the mechanism motion reliability of large overloading of the late start of the study [1, 2]. In $80 \mathrm{~s}$, Sandler and Rhyu studied the influence of the original dimension error of gear and planar four bar mechanism on reliability [3]. In the literature [4-10], the wear process of gear profile was calculated by using Archard wear and Hertz theory, but other factors such as surface hardness and wear depth were not considered $[11,12]$.

This paper takes a lift with big modulus gear and rack structure as the research object, a detailed analysis of the Archard wear theory when the impact factor, through different wear surface hardness changes, and establish reliability of gear rack movement in different wear or life were calculated.

\section{Time-Variant Wear Model and Influence Factors}

The structure of the rack and pinion is a line contact, and the motion of the active part is transferred to the passive part by direct contact. Therefore, with the increase of the running time of the gear rack, the change of the surface shape in the wear process will lead to the change of the motion law, which will affect the reliability of the equipment operation.

Due to the wear of complex factors, it is difficult to find analytical expressions to describe precisely the wear surface changes, so consider using approximate numerical method, the gear rack continuous wear process of discretization, the wear problem can be attributed to wear for finite element node, as shown in Figure 1. Here used to describe the friction wear step in motion in the process of a series of discrete state, a micro amount of wear parts is as a wear step (time ranging) $[5,14]$. 


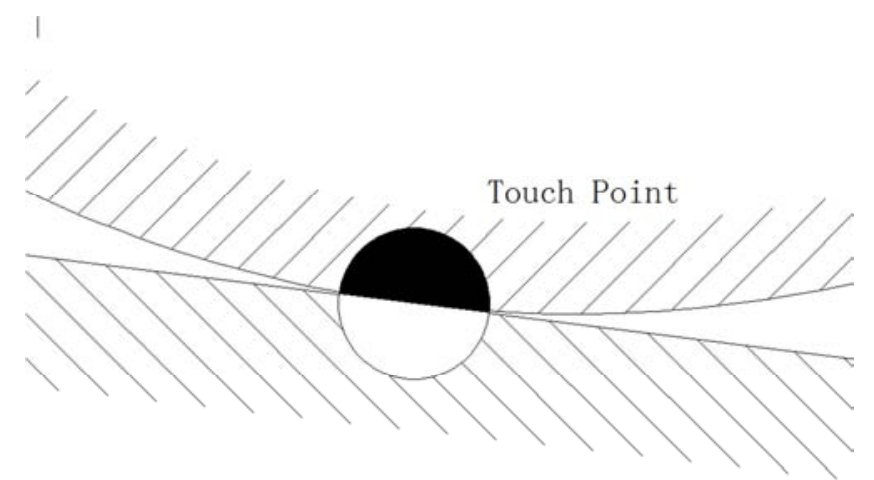

Figure 1. Discrete contact points.

\subsection{Gear Wear State Parameter}

The Archard wear model was proposed by Professor J. F. Archard in 1953, which is suitable for studying the wear characteristics of elastomers. This is similar to the wear mechanism of large modulus gear pair. Therefore, it can be used to analyze and establish the time-varying wear model of gear and rack. The wear model is:

$$
\frac{V}{S}=\frac{k \cdot F_{n}}{H}
$$

In the formula, $\mathrm{V}$ and $\mathrm{S}$ are respectively the volume wear and relative slip distance, $F_{n}$ is the normal force, $\mathrm{K}$ is the dimensionless wear coefficient, $\mathrm{H}$ is the Brinell hardness of the material. The relationship between wear depth and wear coefficient, sliding distance, contact stress and hardness is given. A large number of experiments have proved that the wear rate of the rack is directly proportional to the relative sliding distance and the surface hardness. If the gear rack pair contact area is A, the wear depth is $\mathrm{h}[4]$ :

$$
\left\{\begin{array}{c}
V=A \cdot h \\
\sigma=\frac{F_{n}}{A}
\end{array}\right.
$$

According to the finite element method of gear and rack wear, the wear amount of normal differential element can be expressed by formula (1) and (2):

$$
\Delta \mathrm{h}_{i, j}=\frac{k_{i, j} \cdot L_{i, j} \cdot \sigma_{i, j}}{H_{i-1, j}}
$$

Among them, $\mathrm{L}_{\mathrm{i}, \mathrm{j}}$ for the I wear step tooth contact on the $\mathrm{J}$ contact point from entering into contact with contact friction travel through this interaction period; $\mathrm{H}_{\mathrm{i}-1, \mathrm{j}}$ as the surface hardness of the I-1 wear step after tooth contact in the $\mathrm{J}$ contact point; $\mathrm{k}_{\mathrm{i}, \mathrm{j}}$ as the material wear coefficient under certain conditions $\mathrm{J}$ at the contact point, which is a dimensionless parameter; Sigma $_{\mathrm{i}, \mathrm{j}}$ for the I wear step tooth contact on the $\mathrm{J}$ contact point of contact stress. In the Archard model, the wear coefficient is defined as the probability of producing grain, but this coefficient contains in addition to all the factors affecting wear load $F_{n}$ and sliding distance of $L$, the hardness of the surface materials of $\mathrm{H}$, many scholars at home and abroad for the Archard wear model has done a lot of research and experiments, the wear coefficient selection is rich can reference, also can be obtained according to the experimental data or actual wear monitoring [15-20].

\subsection{Time-Variant Influence Factor}

In the practical application of the project, the key parts of the important equipment are often treated by surface treatment, and the hardness of the surface is much higher than that of the raw material itself. With the equipment running time increases, the wear volume increases gradually, will cause the surface properties of the material changes, it is necessary in the time dimension of wear affects the hardness and depth of the relationship for further study.

Considering the absence of internal defects, the hardness of the surface to the center of the rack is generally decreased. Therefore, the nonlinear function fitting method can be used to analyze the hardness and depth data of the same batch and the same process:

$$
H_{i, j}=\mathrm{f}\left(\sum_{i=1} \Delta h_{i, j}\right)+H_{0, j}
$$

Among them, $\mathrm{H}_{\mathrm{i}, \mathrm{j}}$ is the first $\mathrm{I}$ wear step after contact on the $\mathrm{J}$ contact point on the surface hardness; $\mathrm{H}_{0, \mathrm{j}}$ for the first $\mathrm{J}$ contact points on the surface of the initial hardness. In particular, different surface depths can be expressed as the sum of the wear quantities from 1 to I. It can be known that the surface hardness of parts to calculate the hardness of different depths, in which the fitting function $f(h)$ approximation (hardness testing data) determines the accuracy of the calculation.

\subsection{Time-Variant Wear Model}

Based on the discrete finite element method, the relationship between the hardness and the wear amount is added to the Archard model, and the recursive formula of the wear amount of the element is obtained after the first I wear step:

$$
\Delta \mathrm{h}_{i, j}=\frac{k_{i, j} \cdot L_{i, j} \cdot \sigma_{i, j}}{\mathrm{f}\left(\sum_{i=1} \Delta h_{i-1, j}\right)+H_{0, j}}
$$

In the standard spur gear rack, wear performance of normal contact distance of center distance increases, so you can get any $\mathrm{t}$ time, which is a finite $\mathrm{I}$ wear step, the cumulative gear rack pair time-varying wear:

$$
\begin{array}{r}
\mathrm{h}_{i, j}(\mathrm{t})=\int_{0}^{T} \Delta h_{i, j}(t) d t \\
\mathrm{~h}_{i, j}(\mathrm{t})=\Delta \mathrm{h}_{i, j}+\Delta \mathrm{h}_{i-1, j}
\end{array}
$$

You can get the original clearance time $\Delta^{*}+t$ cumulative wear amount:

$$
\Delta(\mathrm{t})=\Delta^{*}+\mathrm{h}_{i, j}(\mathrm{t})
$$

\section{Time-Variant Reliability Modeling}

Monte Carlo simulation method is also called statistical simulation test method, statistical test method, stochastic 
simulation method, referred to as Monte Carlo method. Monte Carlo method is based on the known probability distribution of random variables, through the random sampling of random variables or random simulation test to estimate and describe the function of the statistics. In this paper, Monte Carlo simulation is carried out to analyze the motion error caused by the random error variables such as the dimension of the gear rack and the meshing, and to evaluate the reliability of the gear rack under the influence of time-varying wear. The specific reliability simulation analysis block diagram is shown in Figure 2.

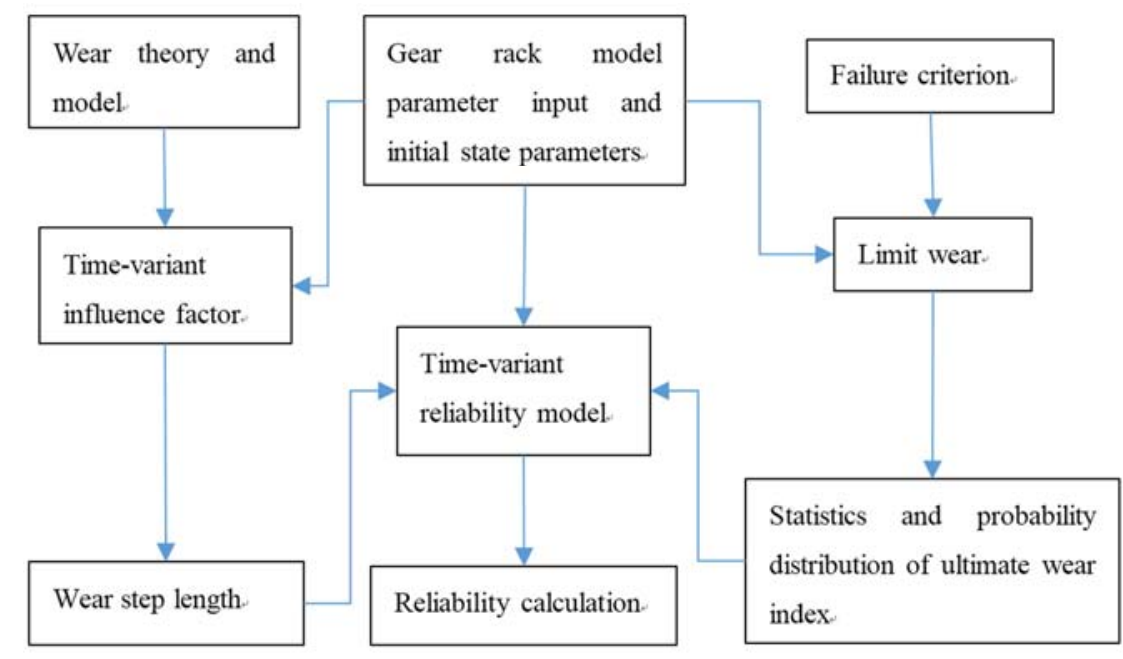

Figure 2. Reliability simulation analysis.

The rack and gear can be used as the basis for reliability calculation according to the relevant criteria, such as the wear failure criterion, the correct meshing and surface hardness. The specific simulation steps:

(1) According to the law of error distribution, the random variables of the variables in the model are sampled randomly, and the sample size of $\mathrm{N}$ with a given sample space capacity is $X_{i}$;

(2) The wear variable is added to the sample $\mathrm{Xi}$ in the given wear step, and the numerical solution is obtained by substituting the time-varying wear model, and the maximum deviation of the meshing motion is obtained $\mathrm{S}_{\max }$;

(3) The sample maximum deviation or whether the wear failure criteria, namely the correct meshing $\mathrm{S}_{\max }$ is less than or equal to $[\mathrm{S}]$ with, remember:

$$
\mathrm{M}=\left\{\begin{array}{l}
1, S_{\max } \leq[S] \\
0, S_{\max }>[S]
\end{array}\right.
$$

(4) Repeat (1) (3) steps, get the number of $S_{\max }$ is less than or equal to [S] limited test in a certain time in t. The reliability is obtained by the theorem of large numbers.

\section{Probabilistic Analysis of Gear Rack Motion}

Usually the gear rack manufacture and installation of the gap size error meshing movement deviation, the reliability index for certain number of meshing or running time under the actual deviation is not greater than the maximum allowable deviation of the wear threshold. In this paper, the correct meshing gear rack on the basis of the coincidence degree to meet the maximum end $[\varepsilon]$ coincidence degree requirements, take with clearance gear rack relative at time $t$ gear axis deviation as the evaluation of gear rack meshing movement. Therefore, the problem can be transformed into the reliability of gear rack engagement:

$$
\mathrm{R}=\mathrm{P}\left[\left(\varepsilon_{\max }-[\varepsilon]\right)<0\right]
$$

It is known that the large module gear rack structure of a ship lift is shown in the following Figure 3, the parameters are as follows [4]:

The gear rack modulus $\mathrm{m}=63, \mathrm{z}=16$ gear, pressure angle alpha $=20$ degrees, the elastic modulus of gear rack $\mathrm{E}_{1}=$ $209000 \mathrm{MPa}, \mathrm{E}_{2}=202000 \mathrm{MPa}$, density $\rho_{1}=\rho_{2}=7850$, Poisson's ratio $\mu 1=0.271, \mu 2=0.3$; torque $\mathrm{T}=453000$ $\mathrm{KN}^{*} \mathrm{~mm}$, wear coefficient $\mathrm{k}=3.6 \times 10^{-8}$, gear rated speed is equal to $1000 \mathrm{r} / \mathrm{min}$.

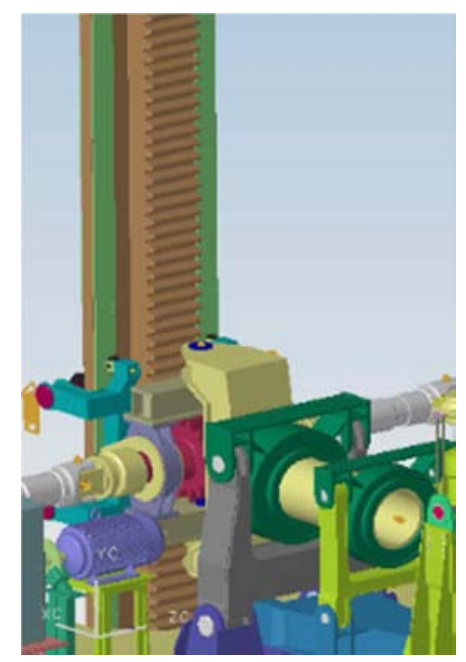

Figure 3. Rack and gear drive mechanism. 
Under normal circumstances, the errors of manufacture and measurement are normally distributed, it can be seen that the actual gear rack installation and operation position should be in the range of deviation from normal distribution [21, 22]. Based on the assumption that the error distribution of mechanical manufacturing is normal distribution, two important assumptions are put forward:

First, the meshing accuracy of the rack and pinion manufacturing error is the normal direction along the tooth surface. The conversion is equivalent to a vertical gear in the direction of the direction of the connection between the gear rack and pinion connecting rod $\mathrm{L}_{1}$ (where the center of the gear to the root of the rack distance);

Second, the installation error caused by the gear rotation accuracy of the gear shaft and sleeve gap changes. Based on the theory of effective length model, can get the gear shaft center should wear effect in the range between the inner sleeve and the error motion as shown in the Figure 4, the deviation is determined by the drive system error.

So the distribution function of the rack and pinion: the gear $\mathrm{R}_{1} \sim \mathrm{N}\left(10,(0.14 / 3)^{2}\right)$, and the distance between the center and the connecting rod is $\mathrm{L}_{1} \sim \mathrm{N}\left(10(0.1 / 3)^{2}\right)$. N $\left(\mathrm{a}, \mathrm{b}^{2}\right)$ indicates that $\mathrm{a}$ and $\mathrm{b}$ are normal distribution of mean and standard deviation.

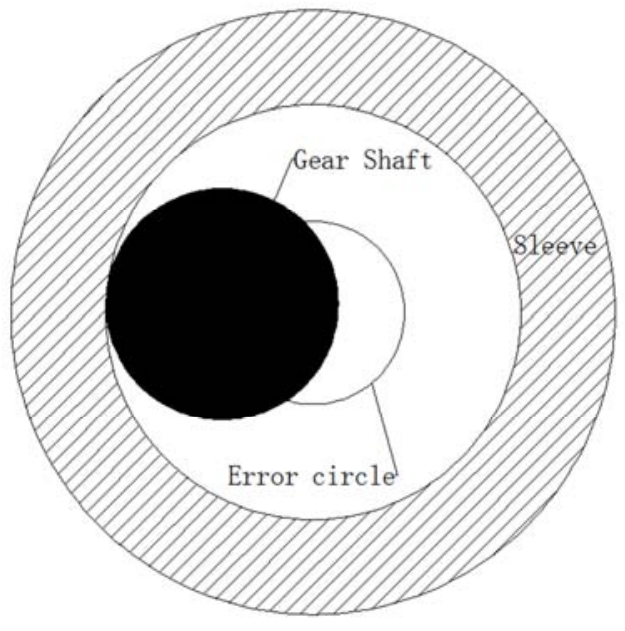

Figure 4. Effective length contact model.

In this case, the gear rack and pinion tooth surface hardening process, the surface hardness of $596 \mathrm{HB}$, from the tooth surface Brinell hardness and hardened layer depth of wear test data as shown in Figure 5 and table 1.

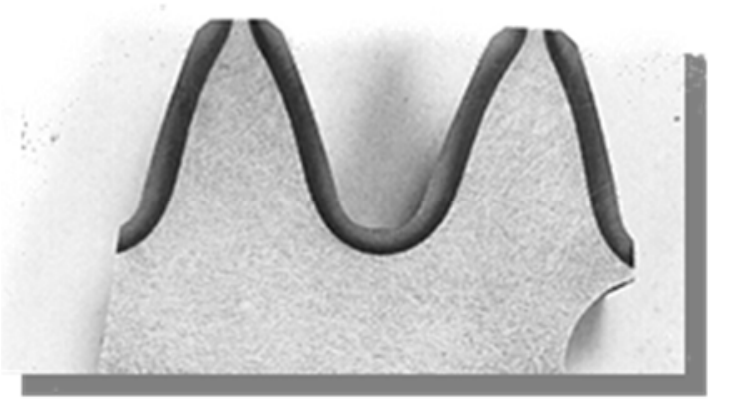

Figure 5. Hardened depth.
Table 1. Rack and pinion hardness at different depths.

\begin{tabular}{lllll}
\hline Depth/mm & \multicolumn{4}{l}{ Hardness/HV } \\
\hline 1 & Point 1 & Point 2 & Point 3 & Point 4 \\
\hline 0 & 609 & 615 & 613 & 610 \\
1 & 612 & 615 & 609 & 612 \\
2 & 607 & 611 & 603 & 605 \\
3 & 590 & 595 & 595 & 587 \\
4 & 579 & 571 & 575 & 574 \\
5 & 547 & 543 & 541 & 544 \\
6 & 503 & 505 & 501 & 506 \\
\hline
\end{tabular}

According to the hardness conversion table and the decrease of the hardness of the surface to the center, the fitting relationship between the Brinell hardness and the wear depth of the hardened layer can be obtained.

The initial state of the gear is set at 0 degrees, and the gear shaft coincides with the inner and outer center of the sleeve. In the numerical simulation, the gear axis is used as the output point.

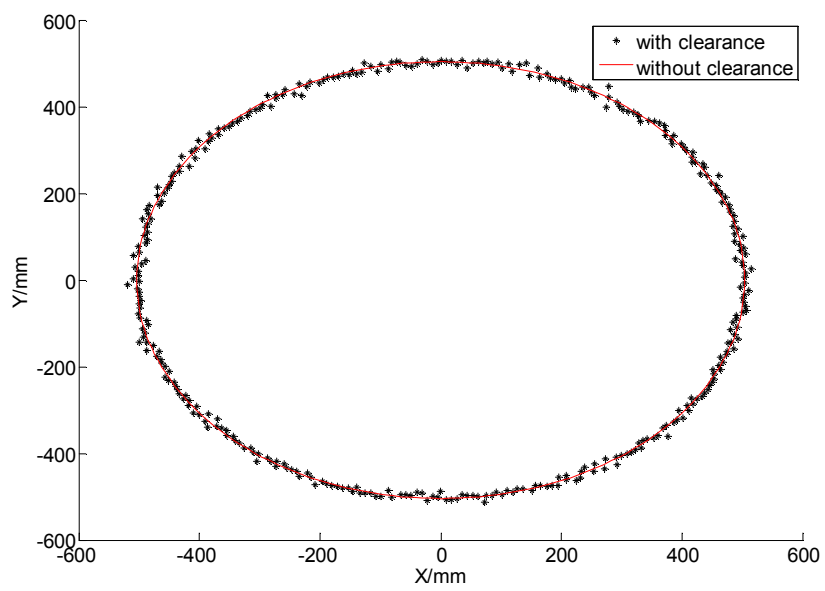

Figure 6. The orbit of the gear axis.

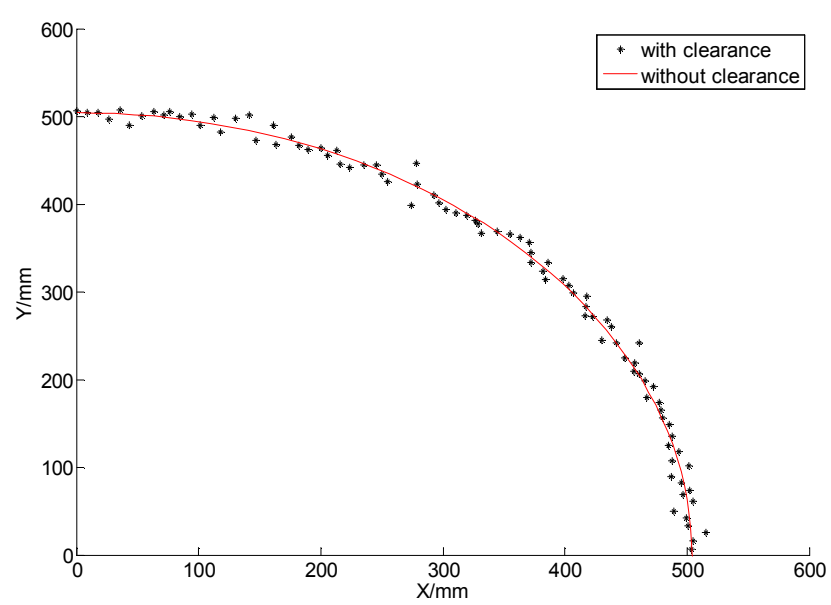

Figure 7. Local view of Figure 6. 


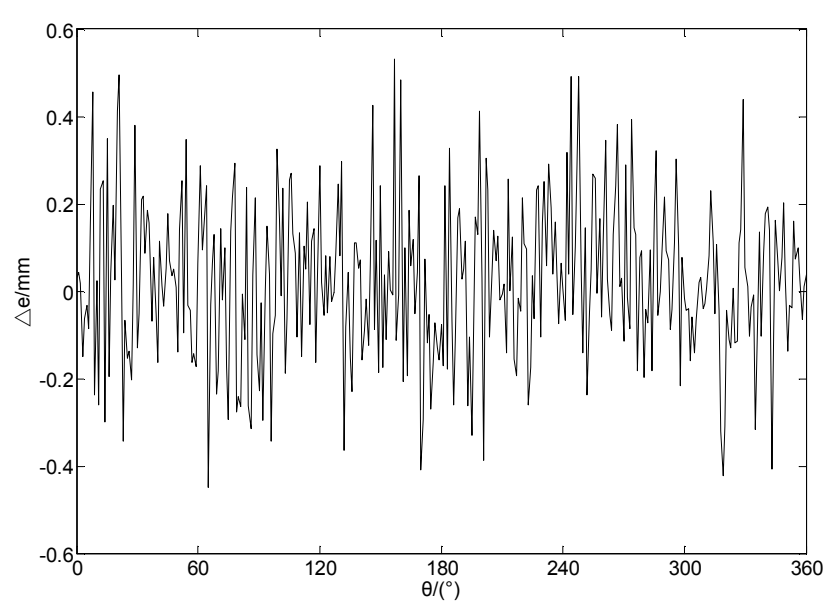

Figure 8. Mark motion deviation.

Figure 6 is the movement of the gear axis, Figure 7 is a partial view of the trajectory. As can be seen from the trajectory, the gap and the ideal trajectory. Figure 8 is the curve of the relative distance between the gear shaft and the rack root, it can be seen that the meshing center distance is affected by the gap error.

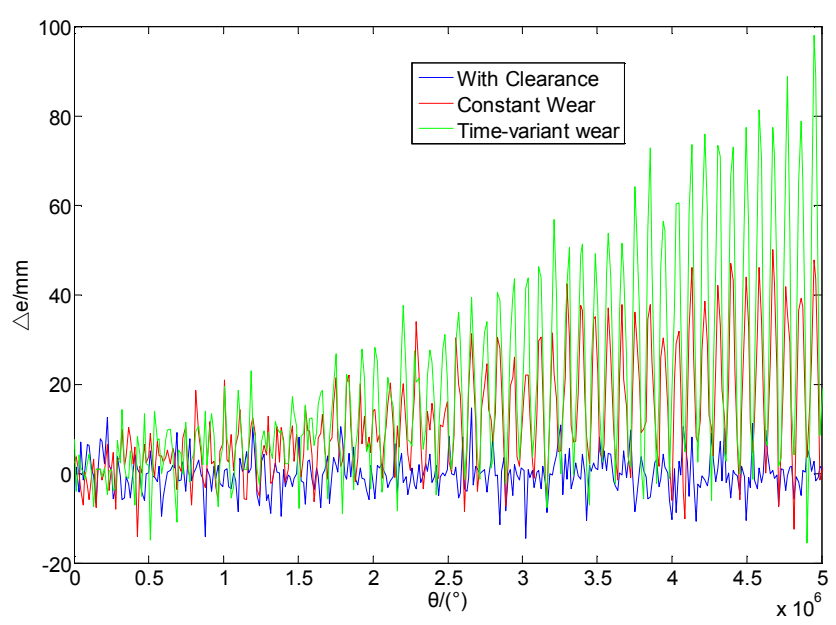

Figure 9. Motion deviation under different conditions.

In order to analyze the relationship between motion deviation and time, the number of loop simulation is set to 5256000 times. Taking the meshing of gear and rack as the wear step, the motion error of the mark point is obtained as shown in figure 9. It can be found that under the condition of installation and clearance error, the rack and pinion motion is smaller than the ideal motion. It can only be used in the research and optimization of equipment or mechanism design stage, but can not be used in the operation of the equipment after a certain period of time and reliability evaluation.

The wear rate does not change with time under the situation, sign the motion deviation increases with the increase in running time, the average performance for the basic linear change values in the wear rate of the accuracy of analysis results depend entirely on motion. The wear process can be divided into running in stage, stable wear stage and severe wear stage, the wear rate with time after degradation, the same to the ascending process. Therefore, the study on the reliability of the rack and pinion under constant wear rate is only applicable to the stable wear stage, and can not be used to analyze the life cycle reliability of the equipment under complex conditions.

According to the time-variant wear gear motion deviation curve can be seen, because the surface hardness degradation effect on load and other conditions are constant, the wear volume gradually increased rapidly, mark point motion deviation and mean changes greatly, time-varying factors have significant influence on the wear and motion state of the gear rack. Therefore, in the calculation of actual movement reliability, it is necessary to wear model and operating conditions to choose the influence of some of the main factors to consider, the simulation model of the calculation results more accurate and reliable.

According to the time-variant wear reliability calculation model, obtained the different meshing number calculation, gear rack movement reliability as shown in Table 2, with the increase of the amount of meshing and wear, gear rack movement reliability decreases quickly.

Table 2. Rack and gear motion reliability.

\begin{tabular}{ll}
\hline Gear revolution & Reliability \\
\hline 241200 & 0.99 \\
331650 & 0.97 \\
361800 & 0.79 \\
391950 & 0.41 \\
452250 & 0.01 \\
\hline
\end{tabular}

\section{Conclusion}

Compared with the ideal structure analysis of the rack and pinion design stage, the gear rack movement will be affected by the manufacturing error, the gap, the wear and the time-varying factors. The time-varying wear model can be used to evaluate the reliability of rack and pinion with time. The manufacturing error and the gap have little influence on the mean and deviation of the moving output, and the influence of the time-varying factors such as wear time increases with the time scale. Therefore, in the calculation of the general accuracy of the instantaneous or short time, the ideal state can be ignored in the calculation. However, it is necessary to consider the analysis of the motion characteristics of the precision machine under the bad working conditions and long service time.

In this paper, the ideal values of other wear factors other than hardness are selected to calculate the reliability results. In order to obtain the reliability of time-varying wear, it is suggested that the measured values of various factors should be put into practice, especially the value of wear coefficient with time.

\section{Acknowledgements}

This research was supported by the National 04 Special Foundation of China under the contract number 
$2012 Z X 0401009103$.

\section{References}

[1] NIU X Q, TAN L M, YU Q K. The design of gear-rack climbing type ship-lift of Three Gorges Project [J]. Engineering Science, 2011, 13(7):96.

[2] CHEN L, CHENG P, SHAO C X. Review of prediction of large modulus gear rack life [J]. Development \& Innovation of Machinery \& Electrical, 2015, 7: 12-13.

[3] S J Lee, B J Gilmore. The determination of the probabilistic properties of velocities \& accelerations in kinematics chains with uncertainty. Transactions of the ASME, 1991, 113(3):84-90.

[4] WANG Decheng, CHEN Li, CHENG Peng et al. Wear and Reliability Life of Large Modulus Gear Rack. 2016 ICRMS.

[5] Rao S S, Bhatti P K. Probabilistic approach to manipulator kinematics and dynamics. Reliability Engineering and System Safety, 2001, 72(8):47-58.

[6] Pfeiffer F, Glocker Ch. Contacts in multibody systems. Journal of Applied Mathematics and Mechanics, 2000, 64(5):773-782.

[7] Flores P. Ambrosio J, Claro J C P, et al. A study on dynamics of mechanical systems including joints with clearance and lubrication. Mechanism and Machine Theory, 2006, 41(3):247-261.

[8] Wang S X, Wang Y H, He BY. Dynamic modeling of flexible multi-body systems with parameter uncertainty. Chaos, Solitons and Fractals, 2008, 36(3):605-611.

[9] Mao K. Gear tooth contact analysis and its application in the reduction of fatigue wear [J]. Wear, 2007, 262(11/12):1281-1288.

[10] LIU B F. Simulation of wear process in spur gear [J]. Mechanical Science and Technology, 2004, 23(1): 55-56.

[11] Lundvall O, Klarbring A. Simulation of wear by use of a non-smooth Nuwronian method-a spur gear application [J]. Mechanics of Structures and Machines, 2001, 29(2):223-238.

[12] Elena Zaitseva, Stefan Kovalik and so on. Algorithm for Dynamic Analysis of Multi-State System by Structure Function [J]. Serbia \& Montenegro, Belgrade, 2005, 11:22-24.
[13] Xinyu Zang, Dazhi Wang and so on. A BDD-Based Algorithm for Analysis of Multistate Systems with Multistate Components [J]. IEEE TRANSACTIONS ON TELIABLITY, 2003, 52(12):1608-1618.

[14] JIANG Q Y, YI F. Probabilistic wear lifetime of hinge configurations resolved on numerical simulation [J]. Chinese Journal of Mechanical Engineering, 2007: 196-200.

[15] ZHANG Y F, LIU Y, et al. Research on Fuzzy Random Reliability Based on Wear Prediction Model [J]. Mechanic Automation and Control Engineering (MACE), 2011 Second International Conference on, 2012(601-604).

[16] KAWAKUBO Y, MIYAZAWA S, NAGATA K, et al. Wear-life Prediction of Contact Recording Head [J]. Mechanic IEEE Transactions on Magnetics, 2003, 39(2): 888-892.

[17] QI G, JIANG G Z, CHUN L T, et al. Reliability Simulation of Fretting Wear based on Neural Network Response Surface in Space Structure Latches [J] Maintainability and Safety (ICRMS), $20119^{\text {th }}$ International Conference on, 2011(58-63).

[18] S. E. Mirbagheri, M. Al-Bassyiouni, A. Dasgupta. Bearing Wear Model for Optical Disk Drive Stepper Motor [J]. Thermal and Thermomechanical Phenomena in Electronic Systems (ITherm), $201213^{\text {th }}$ IEEE Intersociety Conference on, 2012(1274-1280).

[19] Yung-Ruei Chang, Suprasad V. Amari, Sy-Yen Kuo. OBDD-Based Evaluation of Reliability and Importance Measures for Multistate Systems Subject to Imperfect Fault Coverage [J]. IEEE TRANSACTIONS ON TELIABLITY, 2005, 2(4):336-347.

[20] Akhilesh Shrestha, Liudong Xing, Yuanshun Dai. Decision Diagram Based Methods and Complexity Analysis for Multi-State Systems [J]. IEEE TRANSACTIONS ON TELIABLITY, 2010, 59(1):145-161.

[21] Lee S J. Determination of the probabilistic properties of velocities and accelerations in kinematic chains with uncertainty [J]. Journal of Mechanical Design, 1991, 113(1):84-90.

[22] Hongwei Wang, Biao Ma, Hailing Zhang and so on. The Wear Characteristics on Bearing Outer Ring of Planetary Gear in Conflux Planet Gear Train of Power-shift Steering Transmission [J]. IEEE TRANSACTIONS ON TELIABLITY, 2011(8):1252-1256. 